\title{
Frequência genotípica em amostras de MTHFR para 0 polimorfismo C677T em pacientes da cidade de Curitiba-PR
}

Primeira submissão em 27/12/11 Última submissão em 24/09/12 Aceito para publicação em 25/09/12 Publicado em 20/12/12

\section{Genotype frequency in MTHFR samples to C677T polimorphism in patients from the city of Curitiba-PR}

Marcos Edgar Herkenhoff'; Rodrigo Guilherme Backes²; Rodrigo Gaulke; Vanessa Rosália Remualdo ${ }^{4}$

unitermos
MTHFR
Polimorfismo C677T
Frequência genotípica
PCR em tempo real

\section{resumo}

A homocisteína plasmática associada à mutação no gene da 5-metiltetra-hidrofolato (MTHFR) é considerada um fator de risco para doença coronariana. O objetivo deste trabalho foi estabelecer 0 número de indivíduos com essa mutação. Os exames solicitados foram enviados para o laboratório Genolab, abrangendo a cidade de Curitiba- PR. Foi utilizado o método da reação em cadeia da polimerase em tempo real (RT-PCR), tendo como base os laudos para a detecção da mutação C677T em um período dois anos. Vinte e três indivíduos possuíam o genótipo homozigoto C; nove, o homozigoto T; e 35, o heterozigoto. A detecção dessa mutação é importante para uma orientação no tratamento inicial de pacientes que possuem doenças coronarianas correlacionadas.

\section{abstract}

Plasma homocysteine, associated with a mutation in the methyltetrahydrofolate reductase (MTHFR) gene, is regarded as a risk factor for coronary disease. The aim of this study was to determine the number of individuals with this mutation. The exams were sent to the laboratory Genolab, comprising the city of Curitiba-PR. We analyzed reports from a two-year period through real-time $P C R$ method. Twenty-three individuals were homozygous for genotype C, 9 were homozygous for $T$ and 35 were heterozygous. The detection of this mutation is vital to determine the suitable approach in the initial treatment of patients with correlated coronary diseases.

\section{key words}

MTHFR

C677T polymorphism

Genotypes frequency

Real-time PCR

\footnotetext{
1. Mestrando em Ciência Animal, área de Cenética; veterinário.

2. Mestrando em Ciência Animal; técnico em Análises Cenéticas.

3. Graduando em Biomedicina pela Uniasselvi; técnico em Análises Genéticas.

4. Doutora em Patologia; diretora cientifica do Cenolab Análises Cenéticas.
} 


\section{Introdução}

A trombofilia é definida como um aumento na tendência de desenvolver trombose. Vários defeitos genéticos estão associados, entre eles, o acúmulo de homocisteína (Hcy) no sangue $\mathrm{e}^{(9,14,19)}$.

A concentração plasmática de homocisteína é influenciada tanto por fatores nutricionais, como concentração do ácido fólico e vitaminas B6 e B12, quanto por fatores hereditários, especialmente os ligados às enzimas do metabolismo da metionina e da cisteína ${ }^{(1)}$. Na espécie humana, concentrações elevadas de Hcy estão associadas à presença do polimorfismo C677T no gene da 5-metiltetra-hidrofolato (MTHFR), que resulta em termolabilidade e atividade reduzida da enzima $\mathrm{MTHFR}^{(8)}$. Esta, catalisa a conversão de 5,10-metilenotetra-hidrofolato em 5-metileno-hidrofolato, principal forma circulante de folato, o qual é requerido para uma série de vias metabólicas, incluindo a metilação da Hcy para metionina ${ }^{(5)}$.

Evidências experimentais sugerem que a Hcy esteja envolvida na arterogênese e trombogênese, cujas concentrações anormais de Hcy podem ser o resultado da interação de fatores genéticos e nutricionais ${ }^{(18)}$.

Ademais, os problemas ocasionados pela mutação no gene do MTHFR podem ir além da trombofilia. Estudos realizados por Supic et al. ${ }^{(17)}$ e Sailasree et al. ${ }^{(15)}$ demonstraram que essa mutação aliada ao consumo de álcool é responsável pelo aumento de câncer bucal e câncer de mama em mulheres ${ }^{(10)}$. Pode também estar associada a problemas degenerativos ocasionados por uma possível metilação nos telomeros ${ }^{(12)}$, sendo a mitose totalmente dependente de ácido fólico; a presença deste é fortemente influenciada pela mutação na $\operatorname{MTHFR}^{(10,12,15,17)}$.

O objetivo deste trabalho foi quantificar o número de indivíduos homozigotos para o alelo $\mathrm{C}$ e alelo $\mathrm{T}$ e heterozigotos. Os exames solicitados foram enviados para o laboratório Genolab, abrangendo exclusivamente a cidade de Curitiba, no estado do Paraná. Este estudo irá contribuir com a literatura fornecendo dados para consulta da incidência dos genótipos da MTHR em indivíduos dos estados da região sul do Brasil.

\section{Materiais e métodos}

\section{Obtenção e coleta do material}

Utilizaram-se para o presente trabalho, amostras de sangue periférico enviadas pelos laboratórios conveniados ao Genolab, pertencentes aos estados do Paraná e de Santa Catarina. Foi recomendado que a coleta fosse realizada seguindo o manual de coleta Genolab 2010(6).

\section{Extração de ácido desoxirribonucleico (DNA) e amplificação}

Para a obtenção e o isolamento do DNA, utilizou-se a técnica de fenol-clorofórmio(16). Para a amplificação do material genético de interesse, foi aplicada a técnica da reação em cadeia da polimerase em tempo real (RT-PCR) com sonda Taqman ${ }^{\circledR}$, e as concentrações dos reagentes aplicados foram de acordo com recomendações do fabricante (Applied, Foster City, CA). A vantagem de utilizar a RT-PCR é o fato de que essa técnica possui sensibilidade muito maior quando comparada com a PCR polimorfismo de tamanho de fragmentos de restrição (RFLP), também utlizada para a detecção do alelo mutante ${ }^{(7)}$. Além disso, a sonda Taqman ${ }^{\circledast}$ é a sonda mais sensível encontrada atualmente para o uso do RT-PCR, maximizando a sensibilidade da técnica.

\section{Análise dos dados e análise estatística}

Para este experimento, foram coletados os laudos de exames solicitados em nosso laboratório para a mutação C677T, no período do $1^{\circ}$ de janeiro de 2010 a 31 de dezembro de 2010, com todos os pacientes oriundos da cidade de Curitiba-PR. Após a coleta dos dados, eles foram submetidos à análise estatística para calcular a frequência genotípica.

\section{Resultados}

Obteve-se uma amostra de 67 indivíduos. Das amostras analisadas, sete eram homens e 60 , mulheres. Dos indivíduos, 23 possuíam o genótipo homozigoto $C$; nove, o homozigoto T; e 35, o heterozigoto. Do total de indivíduos do sexo masculino, apenas um possuía o genótipo homozigoto $T$; quatro, o homozigoto C; e 2, o heterozigoto. Na amostra do sexo feminino, foram encontrados 19 com o genótipo homozigoto $\mathrm{C}$, oito com o homozigoto T e 33 com o heterozigoto.

A frequência alélica para o alelo $C$ foi de $60,45 \%$ e do alelo $\mathrm{T}$, de $39,55 \%$. Para o sexo feminino, a frequência alélica foi de $59,5 \%$ para o alelo $C$, enquanto para o alelo T, de 40,5\%.

Com base nos dados obtidos pelas frequências alélicas, as frequências esperadas foram de $36,54 \%$ para o genótipo 
homozigoto C, $15,64 \%$ para o homozigoto T e $47,82 \%$ para o heterozigoto na população total. Portanto, a população está em equilíbrio de Hardy-Weinberg.

\section{Discussão}

A frequência para o genótipo homozigoto $T$ apresentou uma taxa similar à de outros trabalhos realizados. Um trabalho de Biselli et al. realizado em 2009 no município de São José do Rio Preto-SP, mostrou uma frequência de 11\% e $9 \%$ para o grupo-controle. O mesmo estudo realizado em Minessota e no norte da Califórnia mostrou uma frequência de $10,53 \%$ para esse mesmo genótipo, somando as dos pacientes com o grupo-controle ${ }^{(4)}$. No Reino Unido, a frequência para esse genótipo foi de $11 \%{ }^{(2)}$.

O genótipo homozigoto $\mathrm{C}$ também apresentou frequência similar à encontrada em São José do Rio Preto, onde a taxa desse genótipo foi de $35 \%$ nos pacientes e $36 \%$ no grupo-controle ${ }^{(3)}$; em comparação com a deste trabalho, foi $34,33 \%$. Em Minessota e no norte da Califórnia, a frequência desse genótipo foi de $45,28 \%{ }^{(4)}$ e no Reino Unido, de $45,9 \%$ (2).

O genótipo heterozigoto também mostrou frequência similar à encontrada em São José do Rio Preto, cuja taxa desse genótipo foi de $54 \%$ nos pacientes e $55 \%$ no grupo-controle ${ }^{(3)}$. Em Minessota e no norte da Califórnia, a frequência foi de $44,19 \%{ }^{(4)}$ e no Reino Unido, de $43,1 \%{ }^{(2)}$.

Os valores em relação às frequências genotípicas demonstraram mais similaridade com a pesquisa realizada em São José do Rio Preto do que com as no Reino Unido e nos Estados Unidos, as quais demonstraram forte semeIhança entre si.

Em relação à frequência alélica, os resultados encontrados foram: $60,45 \%$ para o alelo C e $39,55 \%$ para o alelo $\mathrm{T}$, apresentando apenas um leve aumento na frequência do alelo T em comparação aos demais trabalhos. Em São José do Rio Preto, foi $62 \%$ para o alelo C e $38 \%$ para o alelo $\mathrm{T}$ nos pacientes, e $63,42 \%$ para o alelo $\mathrm{C}$ e $36,58 \%$ no grupo-controle(3). Em Minessota e no norte da Califórnia, os valores encontrados foram de $67,38 \%$ para o alelo C e $32,62 \%$ para o alelo $\mathrm{T}^{(4)}$. No Reino Unido, os valores encontrados também não foram muito diferentes, sendo $67,43 \%$ para o alelo C e $32,57 \%$ para o alelo $\mathrm{T}^{(2)}$.

Apesar de os valores das frequências genotípicas apresentarem valores distintos entre as pesquisas realizadas no Brasil em relação às pesquisas do Reino Unido e dos Estados Unidos, os valores das frequências alélicas foram praticamente os mesmos em todos os trabalhos.

\section{Conclusão}

Os valores encontrados corroboram os valores encontrados em outros trabalhos, possuindo apenas uma leve diferença em relação aos trabalhos realizados nos Estados Unidos e no Reino Unido.

Esses dados servirão como mais um recurso bibliográfico a respeito dessa mutação, principalmente como um dado da região Sul do Brasil, em especial para a cidade de Curitiba-PR.

\section{Referências}

1. ANDREASSI, M. G. et al. Methylenetetrahydrofolate reductase gene C677T polymorphism, homocysteine, vitamin B12, and DNA damage in coronary artery disease. Hum Genet, v. 112, p. 6, 2003.

2. ANTONIADES, C. etal. MTHFR 677 C>T polymorphism reveals runctional importance for 5-methyltetrahydrofolate, not homocysteine, in regulation of vascular redox state and endothelial function in human atherosclerosis. Journal of American Heart Association, v. 119, p. 2507-15, 2009.

3. BISELLI, P. M. et al. Variabilidade genética MTHFR no desenvolvimento da doença arterial coronária. Rev Assoc Med Bras, v. 55, n. 2, p. 274-8, 2009.

4. CURTIN, K.; BIGLER, J.; SLATTERY, M. L.; CAAN, B.; POTTER, J. D.; ULRICH, C. M. MTHFR C677T and A1298C polymorphisms: diet, estrogen, and risk of colon cancer. Cancer Epidemiology, v. 13, p. 285-92, 2004.

5. FINKELSTEIN, J. D. The metabolism of homocysteine: pathways and regulation. Eur J Pediatr, v. 157, p. 404, 1998.

6. GENOLAB. Manual de coleta Genolab. Disponível em: $<\mathrm{http}$ ://www.laboratoriogenolab.com.br/inc/manuais/4 Ofac7537dba75a10491634ba22e1205.pdf>. Acesso em: 25 ago. 2011.

7. GINZINGER, D. G. Gene quantification using real-time quantitative PCR: na emerging technology hits the mainstream. Experimental Hematology, v. 30, p. 50312, 2002.

8. HAVIV, Y. S.; SHPICHINETSKY, V.; GOLDSCHMIDT, N.; ABOU ATTA, I.; BEN-YEHUDA, A.; FRIEDMAN, G. 
The common mutations C677T and A1298C in the human methylenetetrahydrofolate reductase gene are associated with hyperhomocysteinemia and cardiovascular disease in hemodialysis patients. Nephron, v. 92, p. 120-6, 2002.

9. LIMA, L. M. etal. Homocysteine and methylenetetrahydrofolate reductase in subjects undergoing coronary angiography. Arq Bras Cardiol, v. 88, n. 2, p. 144-9, 2007.

10. MARUTI, S. S.; ULRICH, C. M.; JUPE, E. R.; WHITE, E. MTHFR C677T and postmenopausal breast cancer risk by intakes of one-carbon metabolism nutrients: a nested case-control study. Bio Med Central, v. 11, n. 6, 2009.

11. MENA, J. P. et al. Polymorphisms C677T and A1298C in the MTHFR gene in Mexican patients with rheumatoid arthritis treated with methotrexate: implication with elevation of transaminases. The Pharmacogenomics Journal, v. 11, p. 287-91, 2011.

12. MOORES, C. J.; FENECH, M.; O'CALLAGHAN, N. J. Telemore dynamics: the influence of folate and DNA methylation. Annals of the New York Academy of Sciences, v. 1229, n. 1, p. 76-88, 2011.

13. PEREBOOM, I. T. A.; ADELMEIJER, J.; VAN DER STEEGE, G.; VAN DEN BERG, A. P.; LISMAN, T.; PORTE, R. J. Prothrombotic gene polymorphisms: possible contributors to hepatic artery thrombosis after orthotopic liver transplantation. Transplantation: Lippincott Williams \& Wilkins, 2011.

14. SADEGHIAN, S. et al. Homocysteine, vitamin B12 and folate levels in premature coronary artery disease. BMC Cardiovasc Disord, v. 38, n. 6, 2006.

15. SAILASREE, R.; NALINAKUMARI, K. R.; SEBASTIAN, P.; KANNAN, S. Influence of methylenetetrahydrofolate reductase polymorphisms in oral cancer patients. Journal of Oral Pathology Medicine, v. 40, p. 61-6, 2011.

16. SAMBROOK, J.; FRITSCH, E. F.; MANIATIS, T. Molecular cloning a laboratory manual. 2. ed. EUA: Cold Spring Harbor Laboratory Press, 1989. 1886 p.

17. SUPIC, G.; JOVIC, N.; KOZOMARA, R.; ZELJIC, K.; MAGIC, Z. Interaction between the MTHFR C677T polymorphism and alcohol - impact on oral cancer risk and multiple DNA methylation of tumor-related genes. J Dent Res, v. 90, n. 1, p. 65-70, 2011.

18. UPCHURCH JR, G. R. et al. Homocyst(e)ine decreases bioavailable nitric oxide by a mechanism involving glutathione peroxidase. Journal of Biological and Chemistry, v. 272, n. 27, p. 17012-7, 1997.

19. YOSHIOKA, F. K. N.; ARAÚJO, A. G.; TAVELLA, M. H.; HAMOY, I. G.; GUERREIRO, J. F. Prevalence of hereditary risk factor for thrombophilia in Belém, Brazilian Amazon. Genetics and Molecular Biology, v. 29, n. 1, p. 38-40, 2006. 